\title{
AC 2011-1511: SUPPLEMENTAL LEARNING TOOLS FOR STATICS AND STRENGTH OF MATERIALS
}

\section{Cliff J. Lissenden, Pennsylvania State University, University Park}

Cliff J. Lissenden, Ph.D. (University of Virginia, 1993) is a professor of Engineering Science and Mechanics at Penn State. In addition to teaching engineering mechanics courses ranging from sophomore level statics to graduate level mechanical behavior of materials, he researches structural health monitoring for aerospace, mechanical, and civil infrastructure applications. He is a member of ASEE, ASNT, ASME, ASCE, ASM, SES, and Sigma Xi.

\section{Christine B. Masters, Pennsylvania State University, University Park}

Christine Masters is an Associate Professor in the Engineering Science and Mechanics Department at the Pennsylvania State University. In between raising 4 great kids with her husband of 24 years, she has been teaching large enrollment statics and strength of materials courses for the last 10 years and loves every minute of it!

\section{Samia A. Suliman, Pennsylvania State University, University Park}

Samia Suliman, Ph.D. ( Penn State, 2002) is an assistant professor of Engineering Science and Mechanics at Penn State. I addition to teaching engineering mechanics courses she teaches foundational and advanced nano/micro electronics courses. Her research area is power semiconductor devices. she is a member of ASEE, IEEE, NSBE, AAUW.

\section{Roxanne Toto, Pennsylvania State University, University Park}

Roxanne Toto is an instructional designer and e-Learning Support Specialist for the Leonhard Center for the Enhancement of Engineering Education at the Pennsylvania State University, where she works with faculty to implement and assess teaching and learning innovations. Her research interests include instructional design for emerging technologies and assessment of learning in technological environments. 


\title{
Supplemental learning tools for statics and strength of materials
}

\begin{abstract}
Wouldn't it be great to have one more day in statics to try an interactive problem with students during class on something they struggle with (like 3D vectors and moments) without having to sacrifice by doing less example problems? Or have you ever wished your students would come to class at the start of a new unit (like stress transformations) having looked at the topic and with questions based on what they don't initially understand? We may be able to offer some help! Tools have been developed to support learning in statics and strength of materials courses. The intent of the tools is to supplement lectures, textbook, and homework. The tools include (i) two types of videos (concepts and examples) created using Camtasia software and (ii) multiple choice practice problems based on the FE Exam.
\end{abstract}

The concept-based videos are multi-part modules explaining the key aspects of a core course topic, for example stress transformation. Each part of the video is limited to six minutes in an attempt to maintain the viewer's attention and contains an activity to engage the students. The purpose of each module is to ease, not replace, the burden of concept development in class so that more class time can be spent actively applying the concept, interacting with classmates and the instructor. Students can watch a video prior to class as a preview, and then refer back to it when solving homework problems, and preparing for an exam. A consistent theme between the various parts of the video module is maintained by three different instructor narrators. While this was challenging for production, it should increase the likelihood of adoption by engineering mechanics educators with various instructional preferences. The example problem videos are application exercises worked out on a tablet PC where the video captures the pen strokes of the solution as an instructor's voice-over recording explains the thought process involved in each step. These problems can be started in class as an interactive activity without the burden of having to complete the problem during class. After starting the problem in groups, students can be assigned to complete the problem out of class then access the video solution to see if they completed the problem correctly. Perhaps the most valuable feature of these videos is that students can easily play them back and fast-forward them to specific points of interest. The videos themselves become reusable learning objects.

In addition to the two types of videos, multiple-choice problems similar to Fundamentals in Engineering exam problems have been developed in spreadsheet form and are currently being implemented within our course management system. Distracter answers are provided based on common errors, allowing the instructor to set up feedback to the student identifying the error made if a student selects an incorrect answer choice. These problems can be used as out-of-class quizzes, supplemental problems, review problems for exams, or for collaborative learning in class.

Both types of learning support tools (videos and multiple choice problems) are being employed for the first time in two courses on statics and strength of materials during the Fall 2010 semester. This paper will present details of the development of the tools as well as evaluation of assessments acquired during use and at the end of the semester. 


\section{Introduction}

The tools developed for this project are an applied extension of recent work at the Leonhard Center for the Enhancement of Engineering Education at Penn State. We seek to apply what was learned about educational research (related to problem solving, transformational representation, prior knowledge, self-explanations, scaffolding, and worked examples), and translate these ideas into tools that support effective instructional practices. Ongoing work in Statics [1] is aimed at improving student analytical problem solving skills. Predicated on a model that integrates literature on problem solving, representational transformation, and prior knowledge; this first phase identified where students encountered difficulties in the problem solving process. Continued work [2] in Statics, and parallel work, involves the use of Tablet PC developed videos to support student learning. Feedback from these efforts informed the design of the video module presented herein.

The objective of this paper is to encourage instructors of statics and strength of materials at institutions around the country - and the world - to try the supplemental materials described here in their classes. Although the development methodology that we used is summarized, we will save for a future publication instruction on how to create similar materials for these or other topics. These materials are intended to be learner centric and employ readily available technology. Development, usage, and assessment of instructional videos to be viewed by students outside the classroom are described. In addition, the beginnings of a library of application problems akin to Fundamentals in Engineering exam problems is introduced.

\section{Development of Resources}

The design of a video module on stress transformation extends our previous work in statics and with the Tablet PC. The following are brief descriptions of this work as it relates to our rationale for tool development. Building on previous research, the goal of this project is to develop materials that would help improve the effectiveness of the delivery of course content. Specifically, the team wanted to create items that would reinforce the conceptual knowledge students needed to effectively problem solve; facilitate opportunities for interactive problem solving with the instructor; and afford supported practice as students interact with the content material.

\section{Tool 1 - Concept-Based Video Support for Problem Solving}

Problem solving is a complex and multifaceted process that needs to be supported if we are to be successful in helping our students become effective problem solvers. The work in statics [1] deconstructed this process in order to identify where students encountered barriers. This work showed that weak or incomplete domain knowledge was a key factor of student failure. So, any tool or support materials developed should stress and foster engagement with domain knowledge related to the problem. The concept-based videos make transparent the facts, procedures, rules, and rationales necessary to understand the topic and are available to the students to replay at will. Additionally, the videos continually connect concepts with applications while including reasons and alternatives. This will provide learners with an interconnected framework of ideas. 
Feedback garnered from our work on the Tablet PC project [2] indicated that the length of the videos should be no longer than five to seven minutes. This provided us with a target time for clip development for topics and concepts that would optimize their effectiveness. Clearly marked transitions within the clips allow the students to easily move back and forth within the clip facilitating navigation.

The topic of stress transformation spans multiple class periods in the strength of materials course. Realizing that the topic is too extensive for a single video, the topic was subdivided with the instructors on the team each taking responsibility for different parts. Each instructor prepared PowerPoint slides for their parts and the team met to review them. Because all individuals have different styles and instructors have different emphases, it was time consuming and challenging to agree on a uniform style (and notation) and points of emphasis. In the end though, we feel this time was valuable because it should broaden the learning appeal of the presentation relative to what would have been presented by an individual. Development by multiple instructors provides multiple representations and explanations that serve to deepen the learning experience.

After agreeing on the content, notation, and points of emphasis each instructor wrote a script to follow during the recording of the video segment. The videos were recorded from animated PowerPoint slides, oral script, and in some cases a stylus was used to add to the slide or draw attention to key elements of the slide. An iterative process was used by the team to review and edit the slides. After a number of iterations eight video parts of the module were completed and learning objectives were paired with the parts of the module. The motivation/introduction part is the only one which had additional video elements edited into it after the original recording. Finally, each part of the module is produced in multiple formats to facilitate access for the students.

\section{Tool 2 - Worked Examples of Problem Solving}

Worked examples were also developed to support the student problem-solving process. Atkinson et al. [3] describe worked examples as instructional devices that present an expert problem solution with the intent that the example can be used to solve other similar problems. The use of worked examples benefits our current effort for several reasons. First, the worked example by definition provides an expert problem solution that includes explanations and rationales for the problem solving process. This supports the novice problem solver as they follow along because it helps them fill in gaps and reinforces the domain knowledge connected with the problem.

Second, the solutions serve to provide a schema and scaffold for students in the problem solving process, in this instance because they connect theory and application rationales. Scaffolding, as described by Young [4], is an instructional strategy intended to support novice learners by limiting the complexity students encounter as they learn. As the learner gains knowledge, confidence, and skills, the supports can be removed, allowing the learner to become independent and able to succeed at more complex tasks. Third, according to Litzinger et al. [2] "the use of worked examples allows [the learner] to acquire knowledge with far less cognitive load than problem solving." This is because the novice has yet to develop the complex cognitive structure that enables quick and easy problem solving [5]. Lessening the 'cognitive load' through the utilization of worked examples while learning complex materials will facilitate student learning. Fourth, the worked example, by definition, typifies a set of problems that once developed can be 
re-used and replayed. This may also help students connect and apply concepts between and among problems. And fifth, the work in statics [1] suggests that the think-aloud process may support the mapping of knowledge to specific problem states. Think-alouds may also activate prior knowledge to support the application of knowledge during the problem solving process. Our design extends this thought in the worked examples videos, in that the instructor creates an expert think-aloud. It is hoped that this 'expert' think-aloud will help new learners build and map their own knowledge networks.

The problems are worked by hand with a stylus on a tablet PC using Windows Journal. As in the classroom, the instructor describes what she/he is doing throughout the problem solution, while audio narration and ink annotations on the tablet are captured as video using Camtasia.

Typically, multiple takes are required to achieve an acceptable result. Unlike the concept based videos, a script was not used for these worked examples because it was difficult to read a script while simultaneously writing out the solution.

\section{Tool 3 - Practice Problems Based on the FE Exam}

Practice problems were developed based on the FE Exam. These practice examples allow students to engage in problem solving similar to the FE exam. This may facilitate the activation of prior knowledge when and if students take the FE exam. It also allows the learner to engage with multiple representations of similar problems helping to support schema development, provide experience with the problem solving process, and foster confidence and skill development. Repetition and practice provide the learner with the opportunity to condense what is known into smaller, denser cognitive structures. Practice allows a novice learner to apply what is known to new and different situations, allowing them to develop the expertise needed to effectively problem solve. Van Merriënboer [6] argues that schema based learning (such as problem solving) requires feedback at each step of the problem solving process. According to Chi et al. [7], process oriented feedback, such as the feedback provided during practice, can help students pay attention to the problem solving process and support them in developing (or correcting) their own schemas. Feedback for each incorrect response is tailored to indicate the common error or misconception that may have produced the result. In this way students are able to practice independently, yet benefit from information or correction at a critical point in the learning process.

The FE Exam is comprised of multiple-choice questions that have incorrect choices based on common analysis errors. Problems in this style have been developed and implemented in an electronic course management system (ANGEL) such that there are multiple versions having different input values. If a student selects an incorrect choice feedback is provided that indicates the source of the error and the student is given a different version of the same problem. The multiple versions are readily created by automating the problem solution in a spreadsheet. 


\section{Available Instructional Resources}

\section{Tool 1 - Concept-Based Video Support for Problem Solving}

The instructional module consists of eight connected but independent voice annotated videos intended to provide students with supplementary instruction outside of class. Collectively, these videos walk students through the theoretical development and application of the stress transformation equations and Mohr's Circle. While each video part is unique, they contain common elements such as reference to a common set of objectives as well as prompts for conceptual or numerical exercises students can complete during or after each part. The topics and length of each video is listed below and together, they comprise approximately 36 minutes of instruction. Three different instructors narrate the videos to give both a range of perspectives to the overall project as well as auditory variety for the students.

Part 0 - Motivation/Introduction (4:12)

Part 1 - Stress Transformation Equation Development (4:40)

Part 2 - Principal Stress and Maximum Shear Stress Equation Development (5:59)

Part 3 - Visualizing Stress Transformation Equations - Mohr's Circle (4:42)

Part 4 - Mohr's Circle Numerical Example (4:52)

Part 5 - Mohr's Circle Equation Development (3:16)

Part 6 - How to Draw Mohr's Circle (5:00)

Part 7 - 3D Considerations - Absolute Maximum Shear Stress (5:15)

\section{Part 0 - Motivation/Introduction}

Part 0 provides students with a general introduction highlighting the need for the study of stress transformation, introduces general terminology, briefly describes each of the 7 instructional modules, and clearly identifies the learning objectives for the entire set of videos to follow (Figure 1). The objectives slide is so text dense that it is intended to be read 'offline' and objectives specific to each part are re-iterated at the beginning of each part.

Motivation for Stress Transformation

Important question in strength of materials:

How does stress relate to material failure?

Brittle materials:

crushing in compression or fracture in tension - normal stress driven

Ductile materials:

slip -> yielding -> gross plastic deformation - shear stress driven
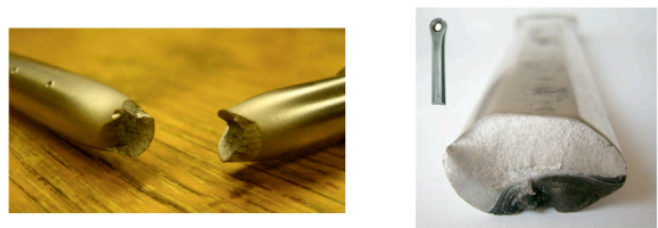

\section{Learning Objectives for Stress Transformation}

1. Identify $2 \mathrm{D}$ stress states

2. Given a $2 D$ stress state in a prescribed coordinate system

a. Apply transformation equations to describe state of stress for any orientation within the plane

b. Apply transformation equations to calculate maximum normal and shear stresses

c. Employ Mohr's circle to calculate maximum normal and shear stresses

d. Calculate the 3D maximum shear stress

-Describe in words the procedure used to develop the stress transformation equations and the maximum normal and shear stresses $(2 a, 2 b)$

- Calculate normal and shear stresses acting on a prescribed plane by drawing a FBD of a wedge and writing equilibrium equations (2a)

-Describe in words principal plane, principal direction, and principal stress (2b)

- Draw the stress state for a prescribed orientation relative to the initial coordinate system (2a) -Summarize the relationship between Mohr's circle and the transformation equations $(2 a, 2 b, 2 c)$ -Highlight the key features of Mohr's circle (2c)

- Describe why the shear stress axis is shown positive downward (2c)

-Explain why $\theta$ at the material point goes to $2 \theta$ in Mohr's plane $(2 c)$

-Draw Mohr's circle for a given stress state, calculate principal stresses, maximum in-plane shear stress, and their orientations relative to the initial coordinate system, draw stress blocks for principal stresses and maximum in-plane shear stress oriented with respect to the initial coordinate system (2c) -State the value of the $3^{\text {ta }}$ principal stress for plane stress (2d) - Draw 3 Mohr's circles and calculate the maximum shear stress (2d)

Figure 1 -Motivation and Introduction Slides from the Part 0 video 


\section{Part 1 - Stress Transformation Equation Development}

Part 1 demonstrates the mathematical development of the general plane stress transformation equations using the static equilibrium of a wedge element as shown in Figure 2. This part of the module also walks students through the trigonometric manipulation of these equilibrium equations to arrive at the standard form of the stress transformation equations.
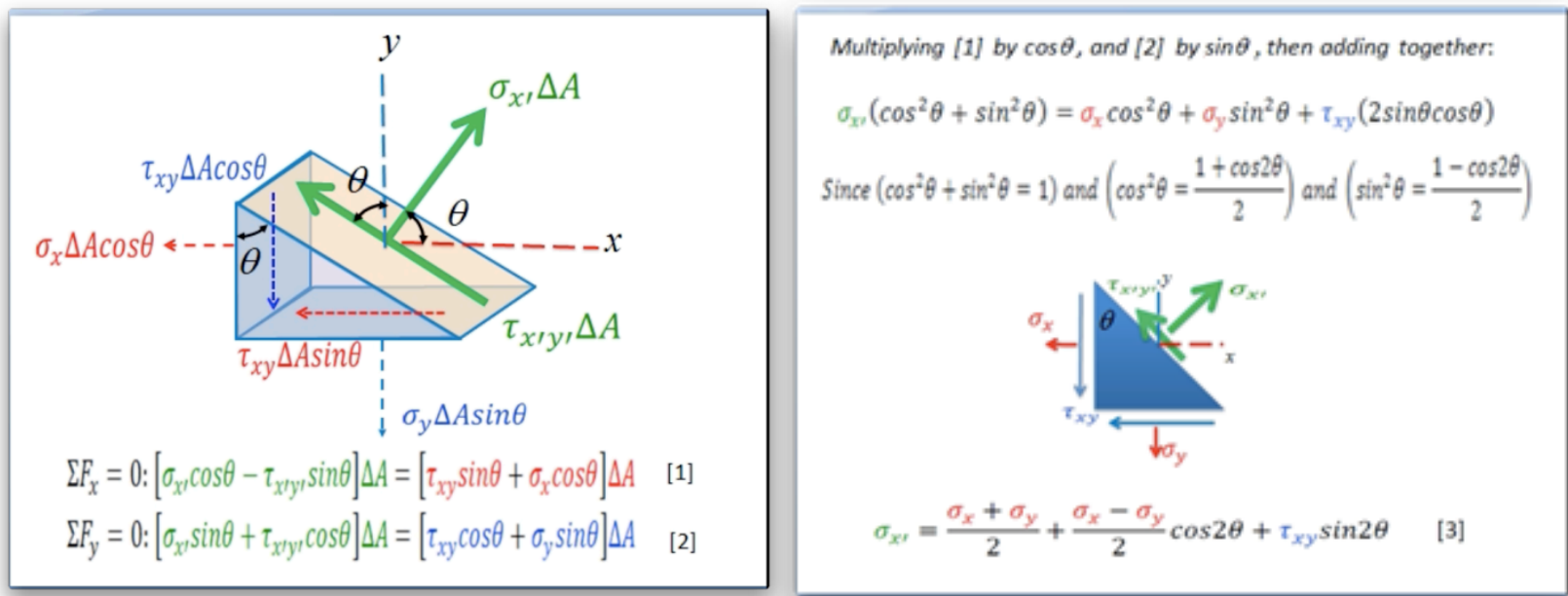

Figure 2 - Static equilibrium and trig manipulation slides from the Part 1 video

\section{Part 2 - Principal Stress and Maximum Shear Stress Equation Development}

The stress transformation equations developed in Part 1 are further manipulated in Part 2 to arrive at the Principal Plane, Principal Stress, and Maximum in-plane Shear Stress transformation equations. Figure 3 shows an image from this video illustrating the equation used to calculate the value of the principal stress plane orientation angle.

\section{Principal Orientation Angles}

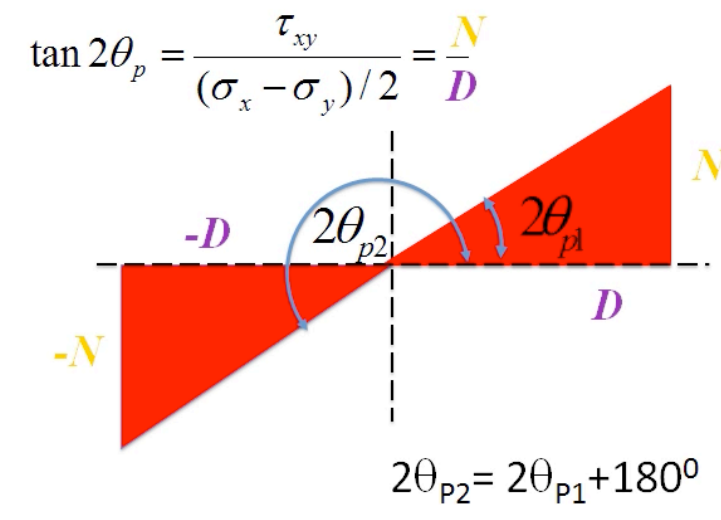

Figure 3 - Graphical illustration of principal plane orientation angle calculation 


\section{Part 3 - Visualizing Stress Transformation Equations - Mohr's Circle}

Part 3 graphically illustrates the relationship between normal stress, shear stress, and orientation angle calculated on the inclined plane using the transformation equations developed in Part 1. Figure 4 provides snapshots of the animation depicting the development of the circular plot of stress points, while Figure 5 shows the standard plot of the circle with the positive shear stress axis down and highlights the relationship between the rotation around the circle and the stress values on the inclined surface of the wedge.

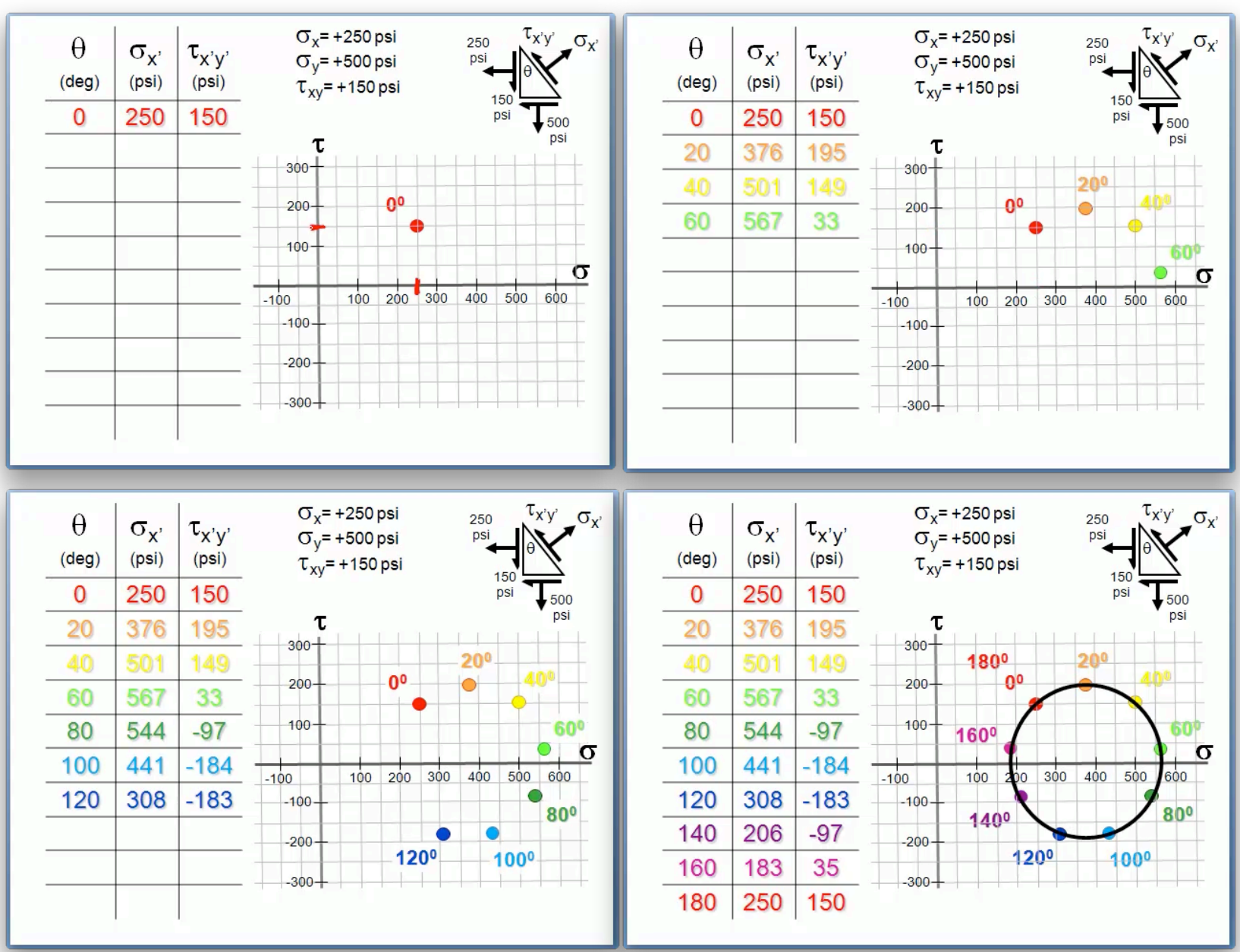

Figure 4 - Development of the circular plot of transformed stress values 


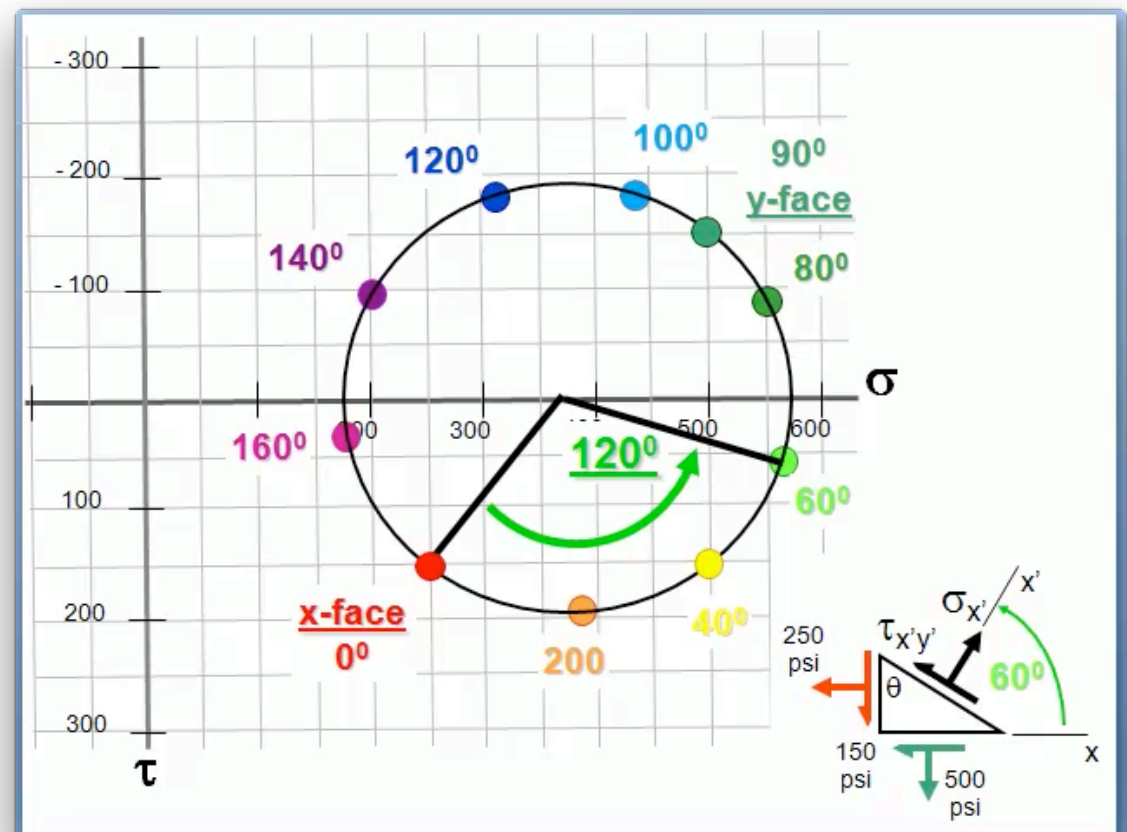

Figure 5 - Angle measurements on the circle compared with angle measurements on the surface of the wedge

\section{Part 4 - Mohr's Circle Numerical Example}

The video module continues in Part 4, where a numerical example walks students through the construction of a Mohr's circle as well as calculation of the principal stress and maximum inplane shear stresses. This part also illustrates the calculation of orientation angles and sketching of elements rotated to the principal plane orientation angles, as shown in Figure 6.
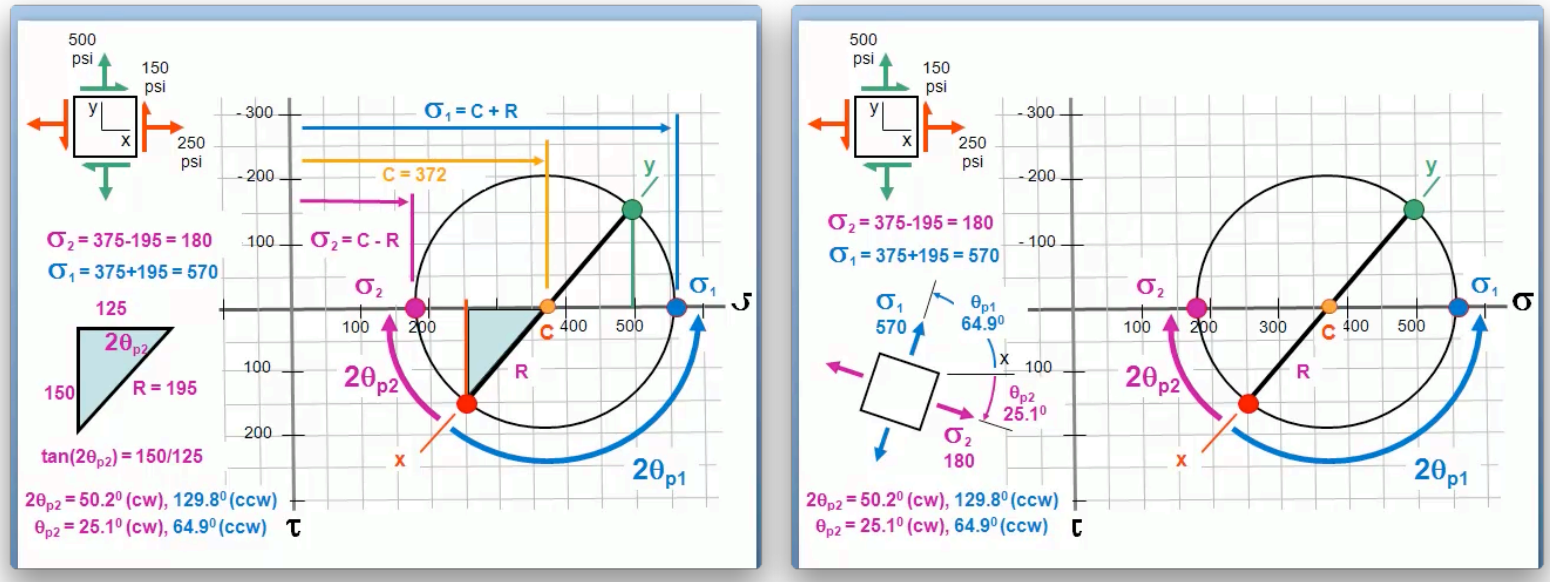

Figure 6 - Numerical Mohr's Circle example 


\section{Part 5 - Mohr's Circle Equation Development}

Much like Part 3, Part 5 begins with the standard stress transformation equations developed in Part 1 and goes on to show the algebraic manipulation of these transformation equations into the equation of a circle. The Part 5 video then goes on to illustrate how this equation can be plotted to produce the same graphical representation of the stress transformation (see Figure 7) as that discussed in Part 3.

Step 4: simplify $\{5\}$

$$
\begin{gathered}
{[\sigma_{x,}-\underbrace{\left.\frac{\sigma_{x}+\sigma_{y}}{2}\right]^{2}+\left[\tau_{x \prime y^{\prime}}\right]^{2}}_{\mathrm{C}}=\underbrace{\left(\frac{\sigma_{x}-\sigma_{y}}{2}\right)^{2}+\tau_{x y}{ }^{2}}_{\mathrm{R}^{2}}} \\
{\left[\sigma_{x,}-C\right]^{2}+\left[\tau_{x \prime y,}-0\right]^{2}=R^{2}}
\end{gathered}
$$

It's a circle

$$
\left[x-x_{0}\right]^{2}+\left[y-y_{0}\right]^{2}=r^{2}
$$

... it's Mohr's Circle!

Center at $(\mathrm{C}, 0)$

Radius $\mathrm{R}$

Max normal stresses and max in-plane shear stress are at key points

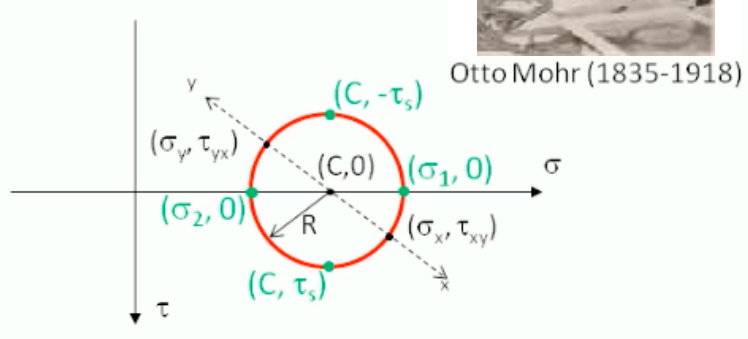

Figure 7 - Equation of circle produced by algebraically manipulating the stress transformation equations. 


\section{Part 6 - How to Draw Mohr's Circle}

To compliment and in contrast to Part 4, Part 6 provides a non-numerical 10-step procedure for constructing and using the Mohr's Circle. The itemized list and detailed images are developed systematically throughout the Part 6 video and culminate in the image shown in Figure 8.

\section{How to draw and use Mohr's Circle}

1. Select a coordinate system

2. Do the stress analysis

3. Draw the Mohr plane and plot $\left(\sigma_{x,}, \tau_{x_{p}}\right)$ and $\left(\sigma_{p} \tau_{p x}\right)$

4. These points are the endpoints of the circle diameter, drawthe circle

5. Use the distance formula to determine length of diameter, $D$, the radius is $R=D / 2$

6. Locate the center of the circle, $(C, 0)$

7. Calculate principalstresses, $\sigma_{1}=C+R$, $\sigma_{2}=C-R$, and maximum in-plane shear stress $\tau_{s}= \pm R$

8. Determine the principal direction, $\theta_{02}$ from geometry of the circle

9. Determine the max in-plane shear stress direction, $\pm 45^{\circ}$ from $\theta_{p 1}$

10. Show stresses of interest on an oriented stress block

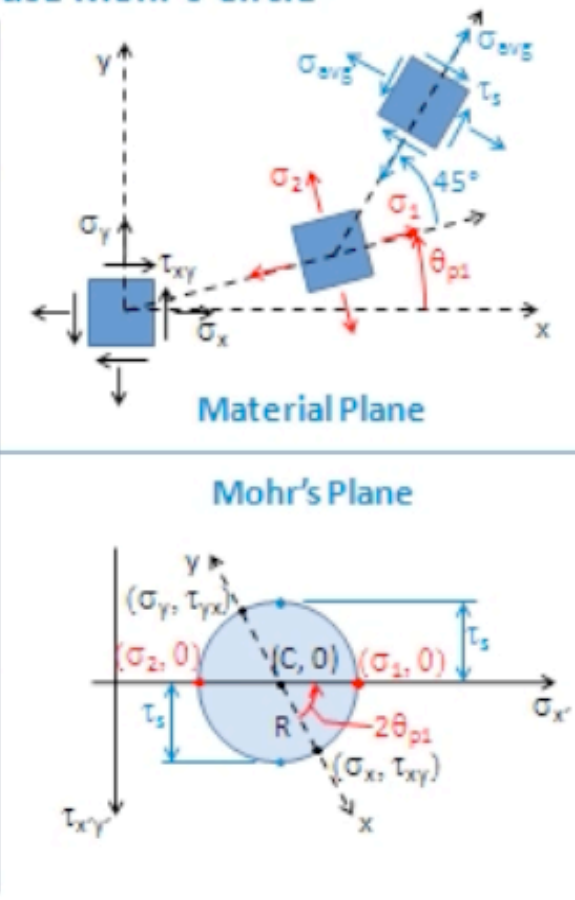

Figure 8 - Illustration of the 10-step process for Mohr's Circle construction 


\section{Part 7 - 3D Considerations - Absolute Maximum Shear Stress}

And finally, the Part 7 video discusses the 3D implications on maximum shear stress, also commonly known as Absolute Maximum Shear Stress. This video graphically illustrates the three different planes to consider for a plane stress situation (Figure 9).

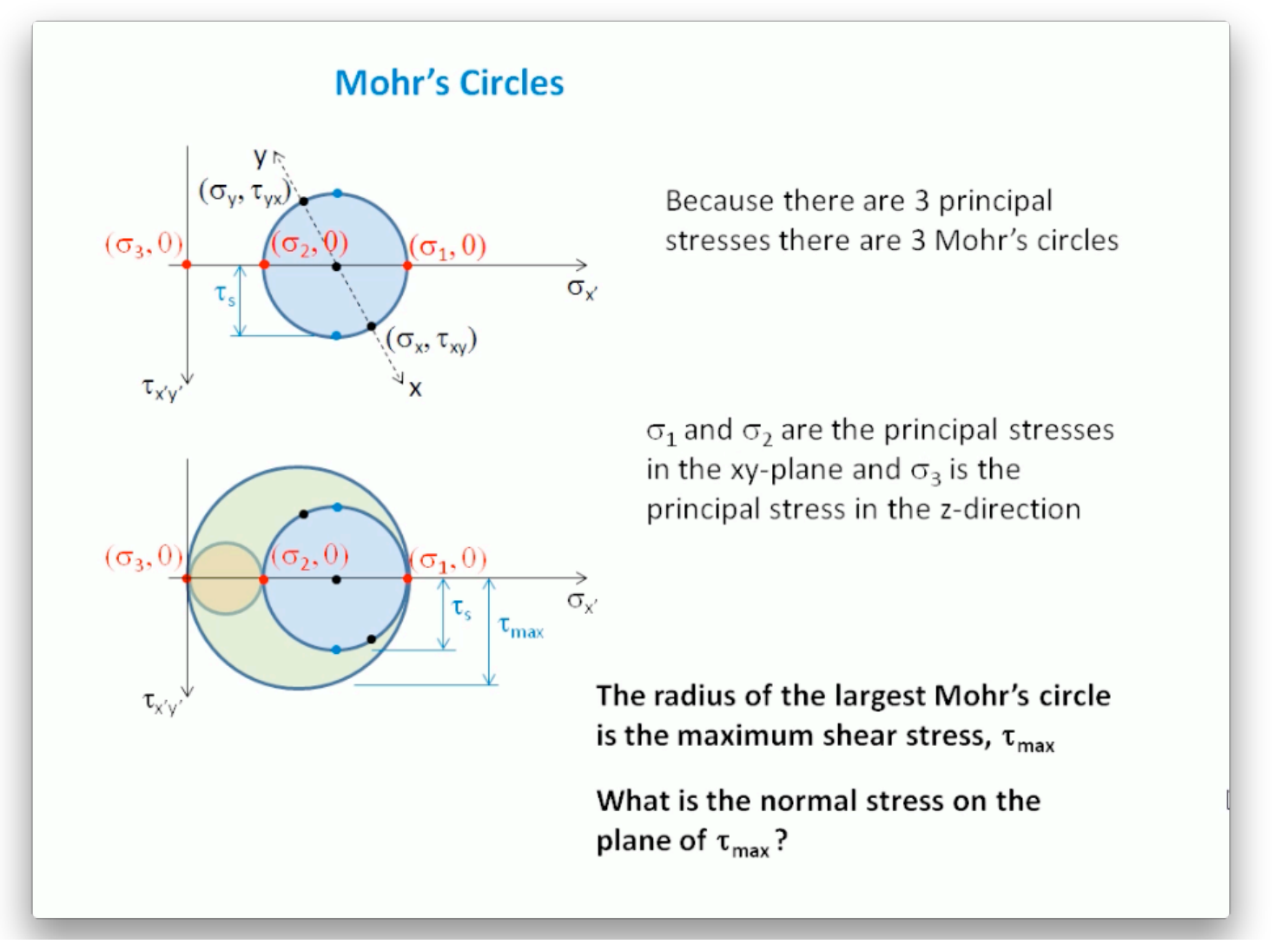

Figure $9-3 \mathrm{D}$ considerations for maximum shear stress calculations

\section{Tool 2 - Worked Examples of Problem Solving}

Eight examples for statics on the topic of force systems are available in MP4 format. These were simply made available to students for download from the course management system. The examples are:

2F Force System Example: Equivalent force (4:45)

2D Force System Example: Parallelogram law (5:46)

Moment Example: Tire Iron using a scalar method (4:06)

Moment Example: Tire Iron using Varignon's theorem (4:00)

Moment Example: Tire Iron using the vector cross product $(3: 58)$

3D Force Example: Fishing Pole (5:32)

3D Moment Example: Fishing Pole (10:07)

3D Force Vector Example: Tractor (9:59). 


\section{Tool 3 - Practice Problems Based on the FE Exam}

The FE Exam style problems cover topics in statics: centroids and moments of inertia (10), systems of forces (6), trusses (10), and strength of materials: stress and strain (5), thermal stress (4), beam deflections (2), combined loading (2), and column buckling (3). Figure 10 shows one of the beam deflection problems.

1.

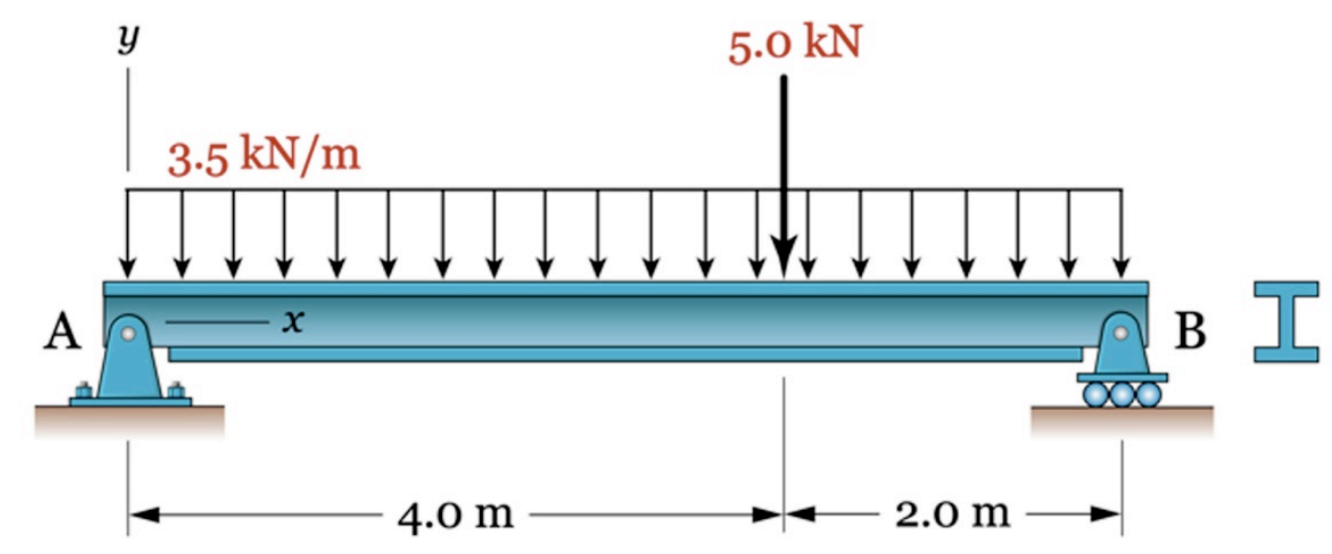

Find the deflection at the center of the beam. Given: $\mathrm{E}=150 \mathrm{GPa}$ and $\mathrm{I}=3.0 \times 10^{7} \mathrm{~mm}^{4}$.

OA) $-6.88 \times 10^{-3} \mathrm{~m}$

OB) $-1.160 \times 10^{-2} \mathrm{~m}$

OC) $-1.740 \times 10^{-2} \mathrm{~m}$

OD) $-8.87 \times 10^{-3} \mathrm{~m}$

Next >

Done Show $/$ Hide Answers

Figure 10 - FE exam style beam deflection practice problem

\section{Application of Resources}

The videos were used in the Fall 2010 semester for E MCH 210 Statics and Strength of Materials (5 credits) and E MCH 210H Statics and Strength of Materials - Honors (5 credits). The videos were used to supplement conventional learning (lecture, textbook, homework). Students were asked to prepare for each class period on stress transformation by watching 2 or 3 parts of the stress transformation video module (Tool 1). Students were then encouraged to use the stress transformation videos however and as often as they like. It was pointed out that the videos are dense with content and that pausing to think and replaying certain parts could be very helpful. The expectation was that students would use the videos to help solve homework problems and prepare for exams. While each part of the module suggests that students actively do something during or after viewing, this was not a required part of either course. 
The worked examples of problem solving (Tool 2) were made available for students to download from the course management system after the associated topic was covered in class. In one case (equivalent force), the problem was introduced during class and students were asked to collaboratively work through an approach to solve the problem. They had approximately 5 minutes in class to do so. They were then encouraged to solve the problem on their own, and finally view the video to confirm that their solution was correct. We believe this to be the most effective use of the worked examples that we have found to date.

The library of FE exam style problems (Tool 3) was not ready for use in the Fall 2010 semester, but we anticipate multiple uses for these problems. (1) Collaborative learning in class - ask pairs of students to develop an approach to solve the problem in class, then have them follow that approach on their own outside of class and check their answer. (2) In-class quiz problems especially useful for large classes because grading of multiple choice problems is not time consuming. Note that partial credit could be awarded based on the severity of the error associated with the wrong choice. However, those who choose by guessing are rewarded rather than penalized. Note that guessing could be discouraged by providing more wrong choices and having penalties associated with guessing them. (3) Out-of-class quiz problems. (4) Review problems for exams.

\section{Assessment of Video Resources}

The video resources were assessed by two voluntary student surveys. One was given immediately after the stress transformation topic was covered in class to provide feedback on the stress transformation video module. The other was given at the end of the semester to assess how the video resources were actually used and how they fit into the overall scheme of student learning.

The students rated their perception of the effectiveness of the video module in supporting their ability to learn how to transform stresses on a scale of $1-4$, where 1 is not effective and 4 is very effective. Table 1 re-orders the 13 prompts related to stress transformation based on highest to lowest mean response. The far-right column provides percentile results; both the percentile of students rating the videos as effective (responses 3 and 4 ) and the percentile of students rating the videos as very effective (response 4 ) are shown. These percentiles appear to be more effective than mean and standard deviation in sorting out what the videos do best and what could be improved from the students' perspective.

A knowledge check was part of the initial survey. Students were not told that this would be included in the survey and ten students chose not to complete this part of the survey (no class credit was given for participating in the survey). As shown in Figure 11, with one exception, the results were positive with a majority of the students identifying the correct response. Over $83 \%$ of the students correctly identified the principal stress and the maximum in-plane shear stress on Mohr's circle. The exception is the description of the development of the stress transformation equations, where the majority of the students incorrectly selected a rectangular element FBD.

The end-of-semester survey results are shown in Figure 12, indicating how often students watched the videos. The majority of students say they watched the videos once or twice to 
prepare for class, once or twice to help with homework problems, and once or twice to review for an exam. Students were also asked to indicate how helpful the videos were to them.

Responses were on a scale of 1-7, where 1 means 'strongly disagree' and 7 means 'strongly agree'. The raw data for the four assessment items are shown in Table 2 along with data analysis that indicates the mean, standard deviation, and agreement percentiles for the 88 student respondents. The agreement percentiles are computed for: all levels of agreement (somewhat agree + agree + strongly agree), the top two levels of agreement (agree + strongly agree), and strongly agree. The most positive responses were registered for 'helped understand course material better' and 'helped review and study'.

\begin{tabular}{|c|c|c|c|c|c|c|c|c|c|}
\hline$\#$ & $\begin{array}{l}\text { Please rate how EFFECTIVE the video modules } \\
\text { is in supporting your ability to LEARN how to: }\end{array}$ & $\begin{array}{c}\text { Not } \\
\text { Effective } \\
\mathbf{1}\end{array}$ & 2 & 3 & $\begin{array}{l}\text { Very } \\
\text { Effective } \\
\quad 4\end{array}$ & $\underset{\mathbf{n}}{\text { Responses }}$ & Mean & SD & $\begin{array}{c}\%(3+4) / \\
\%(4)\end{array}$ \\
\hline 5 & Explain the key features of Mohr's circle & 1 & 4 & 22 & 30 & 57 & 3.42 & 0.71 & $91 / 53$ \\
\hline 9 & $\begin{array}{l}\text { Calculate principal stresses and maximum in- } \\
\text { plane shear stress from Mohr's circle }\end{array}$ & 1 & 5 & 25 & 26 & 57 & 3.33 & 0.72 & $89 / 46$ \\
\hline 8 & Draw Mohr's circle for a given stress state & 1 & 9 & 22 & 26 & 58 & 3.26 & 0.78 & $83 / 45$ \\
\hline 13 & $\begin{array}{l}\text { Draw } 3 \text { Mohr's circles and calculate the } \\
\text { maximum shear stress }\end{array}$ & 2 & 9 & 25 & 22 & 58 & 3.16 & 0.81 & $81 / 38$ \\
\hline 10 & $\begin{array}{l}\text { Show principal stresses and maximum in-plane } \\
\text { shear stress oriented with respect to the initial } \\
\text { coordinate system }\end{array}$ & 1 & 11 & 26 & 20 & 58 & 3.12 & 0.77 & $79 / 34$ \\
\hline 3 & $\begin{array}{l}\text { Draw the stress state for a prescribed orientation } \\
\text { relative to the initial coordinate system }\end{array}$ & 1 & 13 & 24 & 21 & 59 & 3.10 & 0.80 & $76 / 36$ \\
\hline 4 & $\begin{array}{l}\text { Summarize the relationship between Mohr's } \\
\text { circle and the transformation equations }\end{array}$ & 2 & 10 & 29 & 17 & 58 & 3.05 & 0.78 & $79 / 29$ \\
\hline 2 & $\begin{array}{l}\text { Describe in words principal plane, principal } \\
\text { direction, and principal stress }\end{array}$ & 0 & 10 & 37 & 11 & 58 & 3.02 & 0.61 & $83 / 19$ \\
\hline 6 & $\begin{array}{l}\text { Describe why the shear stress axis is shown } \\
\text { positive downward }\end{array}$ & 3 & 9 & 31 & 15 & 58 & 3.00 & 0.79 & $79 / 26$ \\
\hline 7 & $\begin{array}{l}\text { Explain why at } \theta \text { the material point goes to } 2 \theta \text { in } \\
\text { Mohr's plane }\end{array}$ & 4 & 10 & 27 & 17 & 58 & 2.98 & 0.87 & $76 / 29$ \\
\hline 12 & $\begin{array}{l}\text { State the value of the } 3 \text { rd principle stress for plane } \\
\text { stress }\end{array}$ & 3 & 13 & 27 & 15 & 58 & 2.93 & 0.83 & $72 / 26$ \\
\hline 11 & $\begin{array}{l}\text { Draw stress blocks for principal stresses and } \\
\text { maximum in-plane shear stress }\end{array}$ & 3 & 14 & 26 & 15 & 58 & 2.91 & 0.84 & $71 / 26$ \\
\hline 1 & $\begin{array}{l}\text { Describe in words the procedure used to develop } \\
\text { the stress transformation equations and the } \\
\text { maximum normal and shear stresses }\end{array}$ & 2 & 11 & 36 & 9 & 58 & 2.90 & 0.69 & $78 / 16$ \\
\hline
\end{tabular}

Table 1 - Video module effectiveness perceived by students 


\begin{tabular}{|c|c|c|c|}
\hline \# & $\begin{array}{l}\text { Which statement best describes the development } \\
\text { of the stress transformation equations }\end{array}$ & Response & $\%$ \\
\hline A & $\begin{array}{l}\text { FBD of a rectangular area element, equilibrium } \\
\text { equations, definition of stress }\end{array}$ & 25 & $51 \%$ \\
\hline B & $\begin{array}{l}\text { FBD of a triangular area element, equilibrium } \\
\text { equations, area transformation, definition of } \\
\text { stress }\end{array}$ & 8 & $16 \%$ \\
\hline $\mathrm{C}$ & Area transformation, definition of stress & 3 & $6 \%$ \\
\hline $\mathrm{D}$ & $\begin{array}{l}\text { FBD of rectangular area element, moment } \\
\text { equilibrium, definition of stress }\end{array}$ & 5 & $10 \%$ \\
\hline \multirow[t]{2}{*}{$\mathrm{E}$} & I don't know and don't want to guess & 8 & $16 \%$ \\
\hline & Total & 49 & $100 \%$ \\
\hline
\end{tabular}

\begin{tabular}{|c|l|l|c|}
\hline$\#$ & $\begin{array}{l}\text { Which statement best defines } \\
\text { principal stress }\end{array}$ & Response & $\%$ \\
\hline A & An out of plane normal stress & & $10 \%$ \\
B & A maximum shear stress & & $12 \%$ \\
C & A maximum normal stress & $55 \%$ \\
D & $\begin{array}{l}\text { A shear stress that is equal to the } \\
\text { normal stress }\end{array}$ & 0 & $0 \%$ \\
E & A shear stress that acts on a principal & plane & $27 \%$ \\
\hline & Total & & 0 \\
\hline
\end{tabular}

\begin{tabular}{|c|c|c|c|}
\hline \# & $\begin{array}{l}\text { The } 2 \mathrm{D} \text { stress transformation } \\
\text { equations and Mohr's circle can } \\
\text { best be described as: }\end{array}$ & Response & $\%$ \\
\hline A & Unrelated & 1 & $2 \%$ \\
\hline B & $\begin{array}{l}\text { Somewhat overlapping in } \\
\text { applicability }\end{array}$ & 7 & $14 \%$ \\
\hline C & Equivalent & 37 & $76 \%$ \\
\hline D & Useless & 0 & $0 \%$ \\
\hline $\mathrm{E}$ & I don't know and don't want to guess & 4 & $8 \%$ \\
\hline & Total & 49 & $100 \%$ \\
\hline
\end{tabular}

\section{Given a sketch of Mohr's circle, students were asked to identify:}

\section{the point of principal stress and}

the point of maximum in-plane shear stress
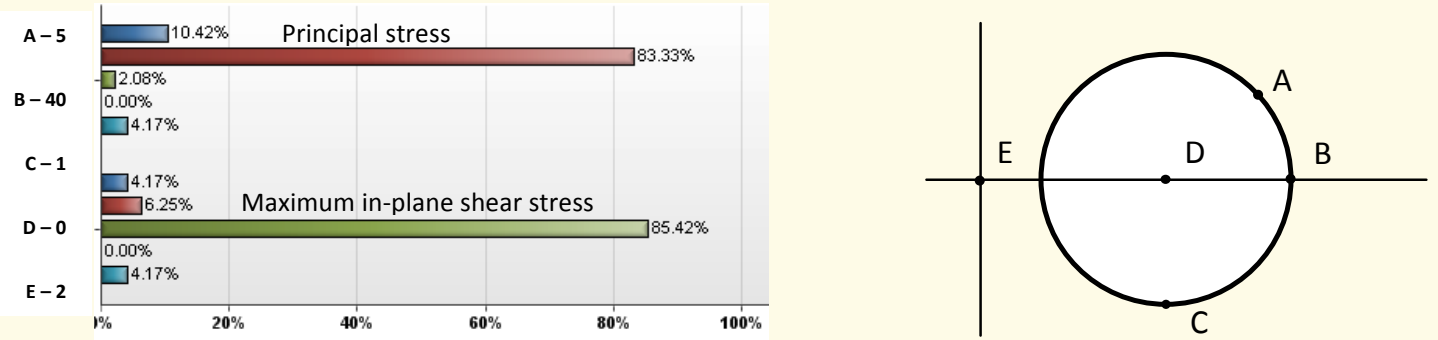

Figure 11 - Results of knowledge check from student survey 
Please indicate how OFTEN you viewed or accessed the video support materials.
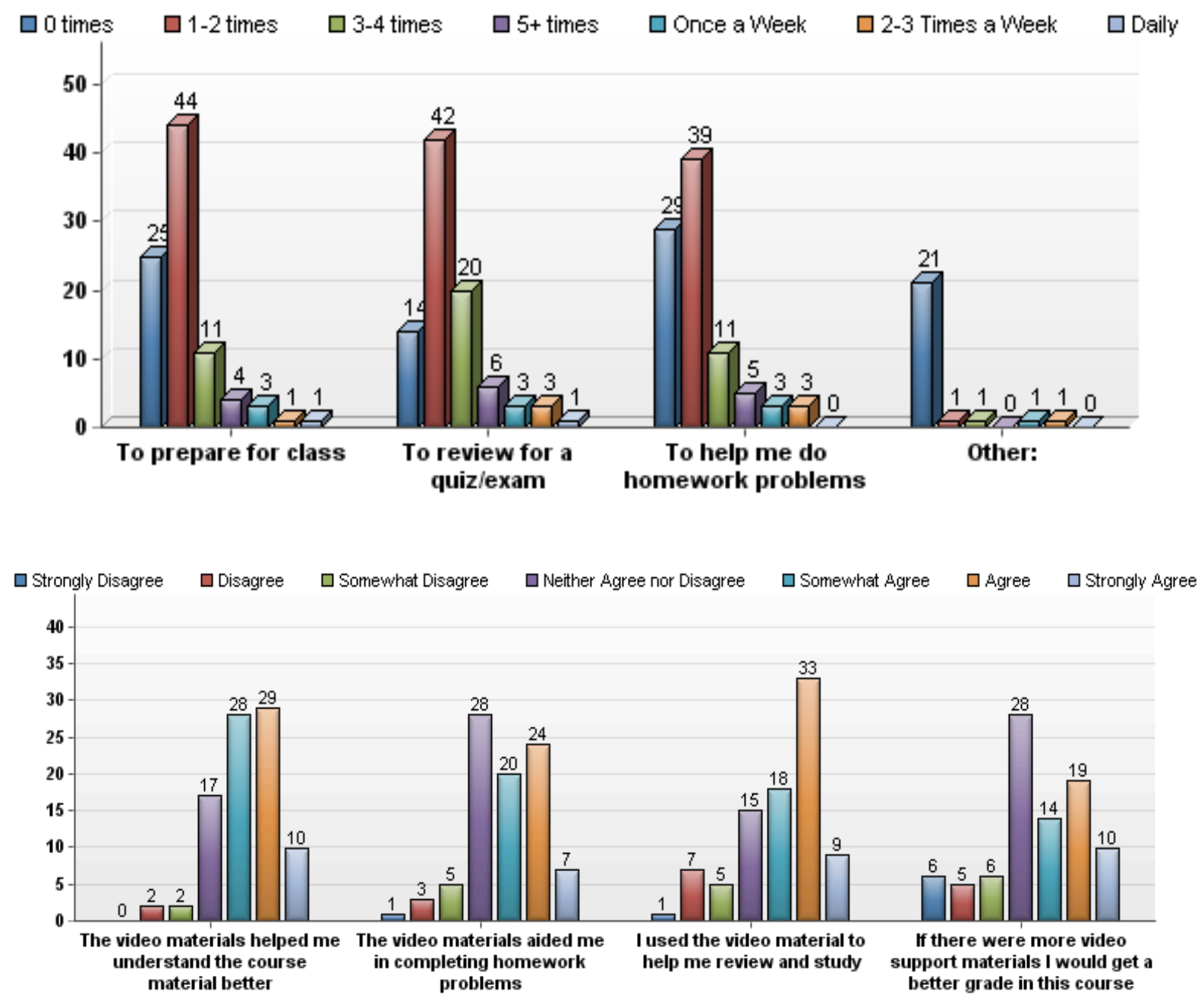

Figure 12 - Student usage of video support materials

\begin{tabular}{|c|c|c|c|c|c|c|}
\hline$\#^{2}$ & ${ }^{2}$ Question & Mean & SD & $\%(5+6+7)$ & $\%(6+7)$ & $\%(7)$ \\
\hline 1 & $\begin{array}{l}\text { The video materials helped me } \\
\text { understand the course material better }\end{array}$ & 5.25 & 1.11 & 76 & 44 & 11 \\
\hline 2 & $\begin{array}{l}\text { The video materials aided me in } \\
\text { completing homework problems }\end{array}$ & 4.85 & 1.27 & 58 & 35 & 8 \\
\hline 3 & $\begin{array}{l}\text { I used the video material to help me } \\
\text { review and study }\end{array}$ & 5.01 & 1.45 & 68 & 48 & 10 \\
\hline 4 & $\begin{array}{l}\text { If there were more video support } \\
\text { materials I would get a better grade in } \\
\text { this course }\end{array}$ & 4.55 & 1.64 & 49 & 33 & 11 \\
\hline
\end{tabular}

Table 2 - Utility of video support materials ( 88 responses) 


\section{Conclusions}

The supplemental learning tools for statics and strength of materials described herein have been found to effectively enhance students' perception of their learning. Best practices for using the videos and FE Exam style practice problems have been suggested. Instructors of statics and strength of materials courses at other institutions are encouraged to try these tools. We welcome, covet in fact, your feedback as development of additional tools is ongoing.

\section{Acknowledgment}

The statics and strength of materials teaching faculty (Lissenden, Masters, and Suliman) acknowledge the support of the Leonhard Center for the Enhancement of Engineering Education at Penn State.

\section{References}

[1] T.A. Litzinger, P.N. Van Meter, C.M. Firetto, L.J. Passmore, C.B. Masters, S.R. Turns, G.L. Gray, F. Costanzo, S.E. Zappe (2010) A Cognitive Study of Problem Solving in Statics. Journal of Engineering Education, Vol. 99, No. 4, pp. 337-354.

[2] T.A. Litzinger, P.N. Van Meter, N. Kapli, S.E. Zappe, and R. Toto (2010) Translating education research into practice within an engineering education center: Two examples related to problem solving, International Journal of Engineering Education, Vol. 26, No. 4, pp 860-868.

[3] Atkinson, R., Derry, S., Renkl, A., Wortham, D., Learning from Examples: Instructional Principles from the Worked Example Research Summer 2000, Vol 70, No. 2. Pp. 181-214

[4] Young, M.F. (1993). Instructional design for situated learning. Educational Technology Research and Development, 41(1), 43-58.

[5] Sweller, J., Cognitive load during problem solving: Effects on learning, Cognitive Science, 12, 257-285 (1988)

[6] Van Merriënboer, J. J. G. (1997). Training complex cognitive skills. Englewood Cliffs, NJ.: Educational Technology Publications.

[7] Chi, M. T. H., Siler, S. A., Jeong, H., Yamauchi, T., \& Hausman, R. G. (2001). Learning from human tutoring. Cognitive Science, 25, 471-533. 